\title{
İş Doyumu ve Yaşam Doyumu İlişkisi: Bir Kamu Kurumu Üzerinde Analitik Bir Araştırma
}

\section{The Relationship Between Job Satisfaction And Life Satisfaction: An Analytical Research On A Public Institution}

Emine Kolbaşı, ${ }^{\text {a* }}$ Zübeyir Bağc ${ }^{\mathrm{b}}$

${ }^{\text {a }}$ Pamukkale Üniversitesi, Sosyal Bilimler Enstitüsü, Yönetim ve Organizasyon Anabilim Dalı, Denizli/Türkiye ORCID: 0000-0001-7228-9585

${ }^{\text {b} D o c ̧ . D r ., ~ P a m u k k a l e ~ U ̈ n i v e r s i t e s i, ~ I ̇ k t i s a d i ~ v e ~ I ̇ d a r i ~ B i l i m l e r ~ F a k u ̈ l t e s i, ~ I ̇ s ̧ l e t m e ~ B o ̈ l u ̈ m u ̈, ~ D e n i z l i / T u ̈ r k i y e ~}$ ORCID: 0000-0001-7902-1485

\section{MAKALE BİLİSİ}

\section{Makale Geçmişi:}

Başvuru tarihi: 17 Ekim 2018

Düzeltme tarihi: 13 Aralık 2018

Kabul tarihi: 09 Ocak 2019

\section{Anahtar Kelimeler:}

İş Doyumu

Yaşam Doyumu

Kamu Çalışanları

\section{ARTICLE INFO}

\section{Article history:}

Received 17 October 2018

Received in revised form 13 December 2018

Accepted 09January 2019

Keywords:

Job Satisfaction

Life Satisfaction

Public Employees
ÖZ

$\mathrm{Bu}$ çalışmada yaşamlarının önemli bir kısmını işyerlerinde geçiren çalışanların iş doyumları ile yaşam doyumları arasındaki ilişki incelenmeye çalışılmıştır. Bu amaçla bir kamu kurumunda çalışan 131 personel üzerinde analitik bir araştırma gerçekleştirilmiştir. Araştırma için gerekli olan veriler anket tekniği kullanılarak toplanmıştır. Hazırlanan anket formunda katılımcıların demografik özellikleri ile iş ve yaşam doyumlarına ilişkin sorular yer almıştır. Katılımcıların iş doyumları Brayfield ve Rothe (1951) tarafindan geliştirilen tek boyutlu "İş Doyumu Endeksi” ile ölçülmüştür. Katılımcıların yaşam doyumları ise Diener ve arkadaşları (1985) tarafından geliştirilen tek boyutlu "Yaşam Doyum Ölçeği" ile ölçülmüştür. Araştırmada analiz yöntemi olarak tanımlayıcı istatistikler ile korelasyon ve regresyon analizleri kullanılmıştır. Yapılan regresyon analizi sonucunda iş doyumunun yaşam doyumu üzerinde anlamlı bir etkiye sahip olduğu belirlenmiştir

\section{A B S T R AC T}

In this study, the relationship between job satisfaction and life satisfaction of employees who spend a significant part of their lives at workplaces was investigated. For this purpose, an analytical research was carried out on 131 staff working in a public institution. The data required for the research were collected using the survey technique. The questionnaire included questions about the demographic characteristics of the participants and their job and life satisfaction. Job satisfaction of the participants was measured by the one-dimensional "Job Satisfaction Index" developed by Brayfield and Rothe (1951). Life satisfaction of the participants was measured by the onedimensional "Life Satisfaction Scale" developed by Diener et al. (1985). Descriptive statistics, correlation and regression analyzes were used as the analysis method. As a result of the regression analysis, it was determined that job satisfaction had a significant effect on life satisfaction

\section{Giriş}

Günümüz iş dünyasında hızla artan küreselleşme ve rekabet ile birlikte teknolojik değişme ve gelişmeler yaşanmaktadır. İş ve çevresini, bu değişen koşullara uyum sağlayabilmesi için yol gösteren temel etkenlerden biri olarak bireyler oluşturmaktadır. Örgütün bireyden beklentilerinin gün geçtikçe artması ile birey hayatının önemli bir bölümünü iş ve çevresinde geçirmektedir. Dolayısıyla bireyin iş yaşantısı artık hayati bir unsur olmaktadir.
İş yaşantısı bireylere ekonomik anlamda yarar sağlamaktadır. Ayrıca örgüt içerisinde yoğun olarak yaşanan iletişim ve etkileşim ile birlikte birey sosyal anlamda da yaşaması gereken ihtiyaçlarını tamamlayabilmektedir. Bu sayede bireyin hem ekonomik hem de sosyal anlamda yakaladığı mutlulukla iş doyumu artarken bir yandan da yaşam doyumunun artma ihtimali oldukça fazla görülmektedir. Genel bir çerçeveden bakıldığında iş doyumu ve yaşam doyumu arasında gözle görülebilir şekilde bir ilişkinin olduğu söylenebilir.

\footnotetext{
* Sorumlu yazar/Corresponding author

e-posta: emineardic0@gmail.com
} 


\section{Kavramsal Çerçeve}

İş doyumu soyut bir kavram olması nedeniyle pek çok araştırmacı tarafından çok sayıda tanımı yapılmaktadır (Özdevecioğlu ve Doruk, 2009: 75). Bozkurt ve Bozkurt'a (2008: 2) göre iş doyumu "kişinin işinde ne kadar mutlu olduğudur". Çarıkçı (2000:155) ise, iş doyumunu "çalışanların işlerinin çeşitli yönlerine karşı besledikleri tutum toplamı" olduğu şeklinde tanımlamaktadır. Genel olarak iş doyumunu "bireyin işine karşı gösterdiği genel tutumdur" şeklinde tanımlayabiliriz. Ancak her birey farklı kişilik yapısına sahip olduğundan, kendine göre işine karşı olumlu veya olumsuz tutum geliştireceğinden dolayı iş doyumu, "bireyin iş deneyimlerinin sonucunda ortaya çıkan olumlu ruh halidir" şeklinde tanımlanırken olumsuz tutum ise iş doyumsuzluğu olarak tanımlanmaktadır (Erdoğan, 1996: 231). Yapılan tanımlamalar incelendiğinde iş doyumunun iki yönü üzerinde durulduğu ortaya çıkmaktadır. Bunlar ilki tutum diğeri ise duygudur. İş doyumu, bir taraftan, kişinin işine karşı olumlu veya olumsuz bir duygu hali diğer taraftan ise işini beğenip beğenmediğini hissetme hali olarak görülebilir (Jalagat, 2016:37).

Yönetici ve çalışanlar için iş doyumu büyük önem arz etmektedir. Örgüt içerisinde iş doyumu sağlanması adına hem yönetici hem de çalışanların sahip oldukları tutum ve duygularından ödün vermeleri gerekebilmektedir. Tutum ve duygulardan ödün verilerek belirli bir dengenin sağlanması ile birlikte örgüt içerisinde yaşanan iş doyumuna bağlı olarak verimlilik, performans, örgüte ve işe bağlılık ve devamsızlık, geç gelme, işe yabancılaşma, işten ayrılma gibi davranışlarda gözle görülür bir farklılık yaşanabilmektedir (Farrel, 1983:596).

İş doyumunu etkileyen faktörler bireysel ve örgütsel olmak üzere iki grupta incelenmektedir (Erdoğan, 1996: 233-234). Bireysel faktörleri ortaya çıkaran sebep bireyin yetiştiği aile ve çevredir. Dolayısıyla bu faktörler, bireyin kişilik özellikleri, yetenekleri, iş yaşam tecrübesi, bilgi düzeyi, sosyal yapısıdır. Örgütsel faktörler ise, işin genel görünümü ve zorluk derecesi, ücret, ilerleme olanağı ve uygun ödüllendirme, beşeri ilişkiler, işletmenin sosyal görünümü, çalışma koşulları ve iş güvenliğidir.

İş doyumunu yeterli düzeyde yaşayan çalışan, hayatından memnun olan, olumlu davranışlar sergileyen, sağlıklı bir psikolojiye sahip olan, iş ve özel hayatında bu olumlu durumu başarıya yansıtan bir birey olarak karşımıza çıkabilmektedir (Demirel, 2014: 4926).

Yaşam doyumu kavramı iş doyumuna benzer niteliktedir. İş doyumundaki gibi yaşam doyumunda da kişilik yapısına bağlı duygulanım söz konusudur (Judge vd., 1998: 31). Yaşam hakkındaki genel duyguları yansıtmakta ve yaşanılan mutluluğun bir ölçüsü olarak görülmektedir. Yaşam doyumu, "kişinin genel hayatını pozitif değerlendirmesinin bir derecesidir" şeklinde tanımlanabilmektedir (Aşan ve Erenler, 2008: 206).

Yaşam doyumunun da iş doyumuna benzer şekilde kişilik, sosyal beklentiler, sosyo-ekonomik faktörler, önemli kişilerle olan ilişki (komşular, ebeveynler, çocuklar), fiziksel ya da psikolojik sağlık, konaklama ve istihdam gibi birçok potansiyel belirleyicisi bulunmaktadır (Argan, 2018:50). Yaşamda belirli bir amacı olan ve hedefine ulaşan bireylerin uygun düzeyde yaşam doyumu yaşadıkları söylenebilmektedir. Özellikle aile bireyleri arasında sağlıklı bir iletişimin olduğu aile ortamında büyüyen çocukların kendilerini iyi hissettikleri ve bunu da yaşamları boyunca davranışlarına olumlu şekilde yansıttıkları görülmektedir (Arıdağ ve Seydooğulları, 2018:3). Bireysel hedeflere ulaşma isteği artan bireyin yaşam doyumunun da artabileceği söylenebilir. Yaşam iş ve iş dışı zamandan oluşmaktadır. Yaşam doyumunda iş doyumu önemli bir paya sahiptir. İş doyumu arttığında direkt olarak yaşam doyumu da artar diyebiliriz. Buna örnek olarak, işinde belirli bir pozisyona gelmek isteyen birey terfisini aldıktan sonra hem ekonomik anlamda hem de sosyal anlamda işine karşı doyum duygusu artacak ve bu da bütün yaşamına yansıdığından dolayı yaşam doyumu da artacaktır. Dolayısıyla yaşam doyumunun bütün hayatımızda oluşan gelişmelere karşı verilen duygusal tepkiler sonucunda ortaya çıkmakta olduğu söylenebilir.

Birey hayatını idame etmek için yaşamının büyük bölümünü işinde geçirmektedir. Bedensel olarak işinden ayrılsa dahi sürekli olarak işini düşünmek durumunda kalabilmektedirler. Bu nedenle yaptığı iş, hayatının büyük bir parçasını oluşturur. Dolayısıyla, yaşam doyumu iş doyumundan ayrı düşünülemez.

Maksim Gorki (1978) yaşam ve iş doyumu arasındaki ilişkiyi "İş bir zevk olduğunda, hayat bir sevinçtir! İş bir görev olduğunda, hayat köleliktir" şeklinde açıklamıştır (Garretto, 2000: 9).

Literatür incelendiğinde çoğu araştırmada iş doyumu ile yaşam doyumu arasında pozitif bir ilişki olduğu görülmektedir (Alghamdi, 2015; Özyer vd., 2015; Aşan ve Erenler, 2008; Avşaroğlu vd., 2005; Rode, 2004). Bununla birlikte iş doyumu ile yaşam doyumu arasındaki ilişkinin negatif yönlü olduğunu (Champoux, 1981) ya da iş doyumu ile yaşam doyumu arasında herhangi bir anlamlı ilişki bulunmadığını (Bergermaier vd., 1984) gösteren araştırmalara da rastlanılmaktadır (Köksal, 2014:55). Bu iki değişkenin birbiri üzerindeki etki gücünü ortaya koymaya yönelik gerçekleştirilen çalışmalar neticesinde üç farklı model geliştirilmiştir. Buna göre saçılma modeli iş ve yaşam tatmini arasında pozitif yönlü bir ilişki olduğunu, giderme modeli iş ve yaşam tatmini arasında yayılmanın aksine negatif yönlü bir ilişki olduğunu, bölünme modeli ise iş ve yaşam doyumu arasında herhangi bir ilişki olmadığını öne sürmektedir (Yenihan vd., 2016:36). Bu üç modele yön veren asıl etken bireyin sahip olduğu kişilik özellikleridir. $\mathrm{Bu}$ sebeple her model farklı bireyde geçerliliğini koruyabilmektedir.

İlgili literatürde gerçekleştirilen çalışmaların bulgularından yola çıkarak bu araştırma kapsamında aşağıdaki hipotez oluşturulmuştur;

\section{$H_{0}$ : Çalışanların iş doyumunun yaşam doyumları üzerinde anlamlı bir etkisi yoktur.}

$H_{1}$ : Çalışanların iş doyumunun yaşam doyumları üzerinde anlamlı bir etkisi vardır.

\section{Yöntem}

$\mathrm{Bu}$ araştırmada, çalışanların iş doyumlarının yaşam doyumları üzerindeki etkisi ele alınmıştır. Araştırma toplamda 215 çalışana sahip olan bir kamu kurumunda gerçekleştirilmiştir. Veriler anket formu aracılığıyla toplanmıştır. Anket formları tüm çalışanlara dağıtılmış ancak 135 tanesi geri toplanabilmiştir. Bunlardan 4 tanesinin değerlendirmeye uygun olmadığı belirlenmiştir. Geriye kalan 131 adet anket 
formu değerlendirmeye alınmıștır. Hazırlanan anket formunda katılımcıların demografik özelliklerini belirlemeye yönelik sorular yanında iş doyumu ve yaşam doyumlarını ölçmeye yönelik sorular yer almaktadır. Çalışanların iş doyumları Brayfield ve Rothe (1951) tarafından geliştirilen "İş Doyumu Endeksi" ile ölçülmüştür. Bu ölçek "işimi severek yaparım”" gibi olumlu ve "işimde zaman geçmek bilmiyor" gibi olumsuz ifadeler içeren 5 sorudan oluşan tek boyutlu bir ölçektir. Ölçek maddeleri 1: Kesinlikle katılmiyorum ve 5: Kesinlikle katılıyorum biçiminde ağırlıklandırılmıştır. Ölçek birçok çalışmada kullanılmış olup geçerlik ve güvenilirliği test edilmiştir (Tutcu ve Çelik, 2018; Doğan ve Aslan, 2018; Cindiloğlu vd, 2017; Büte, 2011; Yürür ve Keser, 2010). Bu çalışmada ölçeğin iç tutarlılık katsayısı $\alpha=0,923$ olarak hesaplanmıştır. Katılımcıların yaşam doyumları ise Diener ve arkadaşları (1985) tarafından geliştirilmiş 5 maddeden oluşan ve çeşitli çalışmalarda (Soylu ve Kabasakal, 2016; Dağlı ve Baysal, 2016; Dost, 2007; Köker, 1991) geçerlik ve güvenilirliği test edilmiş olan "Yaşam Doyum Ölçeği” ile ölçülmüştür. Ölçekte "ideallerime yakın bir yaşantım vardır" ve "tekrar dünyaya gelsem hayatımdaki hemen hemen hiçbir şeyi değiştirmezdim” gibi 5 madde yer almaktadır. Bu maddeler de aynen diğer ölçekte olduğu gibi 1: Kesinlikle katılmıyorum ve 5: Kesinlikle katılıyorum biçiminde ağırlıklandırılmış olup iç tutarlılık katsayısı da $\alpha=0,914$ olarak hesaplanmıştır.

Verilerin analizinde tanımlayıcı istatistikler, korelasyon ve regresyon analizleri kullanılmıştır

\section{Bulgular}

\subsection{Demografik Özelliklere ilişkin Bulgular}

Katılımcıların demografik özelliklerini içeren bulgular Tablo 1 'de verilmiştir.

Tablo 1. Demografik Bulgulara İlişkin Bilgiler

\begin{tabular}{llcc}
\hline Demografik Bilgiler & & $\mathrm{n}$ & $\mathbf{\%}$ \\
\hline \multirow{2}{*}{ Cinsiyet } & Kadın & 28 & 21,4 \\
\cline { 2 - 4 } & Erkek & 103 & 78,6 \\
\hline \multirow{2}{*}{ Yaş } & $<35$ & 46 & 35,1 \\
\cline { 2 - 4 } & $>35$ & 85 & 64,9 \\
\hline \multirow{2}{*}{ Medeni durum } & Bekâr & 26 & 19,8 \\
\cline { 2 - 4 } & Evli & 105 & 80,2 \\
\hline \multirow{2}{*}{ Eğitim } & Lisans & 99 & 75,6 \\
\cline { 2 - 4 } & Lisans öncesi & 32 & 24,4 \\
\hline \multirow{2}{*}{ Çalışma süresi } & 10 Yildan az & 44 & 33,6 \\
\cline { 2 - 4 } & 10 Yildan çok & 87 & 66,4 \\
\hline
\end{tabular}

Yukarıdaki tablo 1'e göre katılımcıların \%21,4'ü kadınlardan, \%78,6'sı da erkeklerden oluşmaktadır. Yaşları itibariyle katılımcıların \%35,1'i 35 yaşın altındakilerden oluşurken $\% 64,9$ 'u da 35 yaşın üzerindekilerden oluşmaktadır. Katılımcıların ağırlığını \%80,2 ile evliler oluşturmaktadır. Çalışma süresine göre katılımcıların \%33,6'sı 10 yıldan daha az bir süredir bu kurumda çalışmayı sürdürürken \%66,4'ü 10 yıldan daha fazla bir süredir bu kurumda çalışmayı sürdürmektedir.

\section{2. Ölçme Araçlarının Geçerlik Analizine İlişkin Bulgular}

Araştırmada kullanılan ölçeklerin geçerlik testleri bilgisayar ortamında LISREL paket programı kullanılarak doğrulayıcı faktör analizleri ile gerçekleştirilmiştir. Doğrulayıcı faktör analizinde modelin değerlendirilmesinde kullanılan bir takım uyum iyiliği indeksleri söz konusudur. Bunlar; kök ortalama kare yaklaşım hatası (RMSEA), benzerlik oranı ki-kare istatistiği (x2), x2/df oranı, uyum iyiliği indeksi (GFI), normlanmış uyum indeksi (NFI), düzeltilmiş uyum iyiliği indeksi (AGFI) ve karşılaştırmalı uyum indeksleri (CFI) biçiminde sıralanabilir (Şimşek, 2007: 47-49). Kullanılan ölçeklerin doğrulayıcı faktör analizi sonucunda elde edilen uyum iyiliği istatistikleri tablo 2'de verilmiştir.

Tablo 2: İş Doyumu ve Yaşam Doyumu Ölçeklerine İlişsin Uyum İyiliği İndeksleri

\begin{tabular}{lccc}
\hline Endeksler & $\begin{array}{c}\text { İş } \\
\text { Doyumu } \\
\text { Ölçeği }\end{array}$ & $\begin{array}{c}\text { Yaşam } \\
\text { Doyumu } \\
\text { Ölçeği }\end{array}$ & $\begin{array}{c}\text { Kabul } \\
\text { Edilebilir } \\
\text { Değerler }\end{array}$ \\
\hline RMSEA & 0,056 & 0,069 & $0,05<\mathrm{RMSEA}<0,10$ \\
$\mathrm{X}^{2} / \mathrm{df}$ & 1,76 & 2,14 & $2<\chi 2 / \mathrm{df}<5$ \\
$\mathrm{GFI}$ & 0,99 & 0,99 & $0,90<\mathrm{GFI}<0,95$ \\
$\mathrm{NFI}$ & 0,96 & 0,97 & $0,90<\mathrm{NF} \dot{\mathrm{I}}<0,95$ \\
$\mathrm{CFI}$ & 0,98 & 0,98 & $0,90<\mathrm{CFI}<0,95$ \\
\hline
\end{tabular}

Tablo 2 incelendiğinde araştırma kapsamında kullanılan ölçeklerin yazında geçtiği şekilde bir faktör yapısına sahip oldukları rahatlıkla söylenebilir. Dolayısıyla ölçeklerin faktör yapılarının doğrulandığı sonucuna varmak mümkündür.

\subsection{Korelasyon ve Regresyon Analizine İlişkin Bulgular}

Çalışanların iş doyumları ile yaşam doyumları arasındaki ilişkinin miktarını ve yönünü belirlemek amacıyla korelasyon analizi gerçekleştirilmiştir. Korelasyon analizinde korelasyon katsayısının mutlak değer olarak $0,70-1,00$ arasında olması yüksek; 0,70-0,30 arasında olması orta ve 0,30-0,00 arasında olması ise düşük düzeyde bir ilişkinin varlığına işarettir (Büyüköztürk, 2003:32). Analiz neticesinde elde edilen ortalama, standart sapma ve korelasyon katsayıları tablo 3'te gösterilmiştir.

Tablo 3: Ortalama, Standart Sapma ve Korelasyon Katsayıları

\begin{tabular}{lcccc}
\hline & Ort. & SS & $\mathbf{1}$ & $\mathbf{2}$ \\
\hline İş Doyumu & 2,994 & 0,360 & $(0,923)$ & \\
Yaşam Doyumu & 2,948 & 0,685 & $0,378 * *$ & $(0,914)$ \\
\hline$* * \mathrm{p}<0,01 ;$ parantez içindeki değerler Cronbach's Alpha değerleridir.
\end{tabular}

Tablo 3'te görüldüğü üzere, çalışanların iş doyumları ile yaşam doyumları arasında pozitif yönlü, orta düzeyde ve istatistiksel olarak anlamlı bir ilişki bulunmuştur. Dolayısıyla çalışanların iş doyumları artıkça buna bağlı olarak yaşam doyumlarının da artacağı söylenebilir. Bu sonuç çalışmanın saçılma modeliyle uyumlu olduğunu göstermektedir.

Daha sonra çalışanların yaşam doyumlarının ne kadarlık bir kısmının iş doyumları ile açıklanabildiğini test edebilmek için basit regresyon analizi uygulanmıştır. Enter yönteminin kullanıldığı regresyon analizine ilişkin bulgular tablo 4'te yer almaktadır.

Tablo 4. İş Doyumunun Yaşam Doyumu Üzerindeki Etkisini Belirlemeye Yönelik Basit Regresyon Analizi Sonucu

\begin{tabular}{lccccc}
\hline \multicolumn{1}{c}{ Değişken } & B & Std.Hata & $\boldsymbol{\beta}$ & $\mathbf{T}$ & $\mathbf{p}$ \\
\hline Sabit & 0,795 & 0,467 & & 1,702 & 0,091 \\
İş Doyumu & 0,719 & 0,155 & 0,378 & 4,638 & 0,000 \\
\hline $\mathrm{R}=0,378 \mathrm{R}^{2}=0,143$ & & & & \\
$\mathrm{~F}=21,513 \quad \mathrm{p}=0,000$ & & & & \\
\hline
\end{tabular}

Bağımlı değişken: Yaşam doyumu

Tablo 4 incelendiğinde iş doyumu değişkeninin yaşam doyumu değişkeni ile anlamlı bir ilişki içerisinde olduğu görülmektedir $\quad(\mathrm{R}=0,378, \quad \mathrm{R} 2=0,143, \mathrm{p}<0,01)$. İş doyumu 
değişkeni yaşam doyumu değişkenindeki varyansın \%14'ünü açıklamaktadırlar.

Standardize edilmiş regresyon katsayısı $(\beta)$ ve regresyon katsayılarının anlamlılığına ilişkin t-testi sonuçlarına bakıldığında iş doyumunun yaşam doyumu üzerinde önemli bir etkiye sahip olduğu görülmektedir. $\mathrm{Bu}$ bağlamda "çalışanların iş doyumunun yaşam doyumları üzerinde anlamlı bir etkisi yoktur" biçimindeki $\mathrm{H}_{0}$ hipotezi reddedilirken, "çalışanların iş doyumunun yaşam doyumları üzerinde anlamlı bir etkisi vardır" biçimindeki $\mathrm{H}_{1}$ hipotezi kabul edilmiştir.

\section{Sonuç ve Öneriler}

Günümüzün zorlu ekonomik koşulları dikkate alındığında bireylerin asgari düzeyde hayatlarını idame ettirebilmeleri için zamanlarının büyük bir bölümünü işlerinde geçirmeleri gerekmektedir. Yaptıkları işin zorluk derecesi, aldıkları ücret, terfi olanakları, arkadaşlarıyla kurdukları sosyal ilişkiler ve iş güvenliği gibi faktörlere bağlı olarak işlerinden memnun olabilecekleri gibi memnuniyetsizlik de duyabilirler. Üstelik bu durum sadece iş ortamıyla sınırlı kalmayıp işyerinden ayrıldıklarında bile bir yanlarının iş ortamında kalmasından ötürü iş dışı zamanlarını bile etkiler hale gelmektedir. Dolayısıyla bireylerin yaptıkları işin, hayatlarının önemli bir parçasını oluşturması nedeniyle yaşam doyumları ile iş doyumlarının birbirinden ayrı düşünülemeyeceğini söylemek yanlış olmayacaktır. Bu çalışmada bireylerin iş doyumları ile yaşam doyumları arasındaki bu ilişki ele alınmış olup yaşam doyumlarının ne kadarının iş doyumlarından etkilendiği bir kamu işletmesinin çalışanları üzerinde incelenmiştir.

Elde edilen bulgular katılımcıların hem iș doyumlarının hem de yaşam doyumlarının ortalamanın üzerinde olduğunu göstermiştir. $\mathrm{Bu}$ bulgu çeşitli araştırmalarda elde edilen bulgularla uyumludur (Tutcu ve Çelik, 2018; Polatc1, 2015; Donuk, 2009). Ayrıca katılımcıların iş doyumları ile yaşam doyumları arasında pozitif yönlü ve anlamlı bir ilişki olduğu ve yaşam doyumlarının tahminlenmesinde iş doyumlarının önemli bir etkiye sahip olduğu belirlenmiştir. Bu bulgular literatürde "saçılma etkisi" diye ifade edilen iş doyumunun yaşam doyumunu pozitif bir şekilde etkilediği söylemine uygun düşmektedir. Gerek yabancı literatürde (Alghamdi, 2015; Naz, 2015; Rode, 2004) gerekse de yerli literatürde (Cindiloğlu vd., 2017; Aydıntan ve Koç, 2016; Yenihan vd., 2016; Yiğit vd., 2011; Turgut, 2010) buna benzer sonuçlara rastlamak mümkündür. Dolayısıyla bulguların mevcut literatür ile uyumlu olduğu söylenebilir.

$\mathrm{Bu}$ çalışma bazı sınırlılıklara sahiptir. Bunlardan ilki çalışmanın belli bir kamu kurumunun çalışanları ile sınırlı olmasıdır. İkincisi hem bağımsız hem de bağımlı değişken anket araçlarından türetilen öznel ölçütler olduğu için, ortak yöntem varyansının olası etkilerinden söz edilebilir. Bir diğer sinırlılık ise verilerin toplanmasında yararlanılan tesadüfi olmayan bir örneklemenin kullanılmasına bağlı olarak bulguların genellenebilirliğine ilişkindir.

$\mathrm{Bu}$ çalışma benzer çalışmalarda olduğu gibi iş doyumu ve yaşam doyumu arasındaki ilişkiyi birkez daha gözler önüne sermiştir. Bireylerin iş ortamından memnun olmaları iş dışındaki yaşamlarını da olumlu etkilemektedir. $\mathrm{Bu}$ da bireylerin performanslarına olumlu yansımaktadır. Çalışanların zihinsel ve psikolojik sağlıklarını inceleyen çalışmalar, özellikle rutin ve monoton işlerde çalışan niteliksiz kişilerin işlerinde yaşadıkları sağlık sorunlarının onların genel yaşam mutluluğunu olumsuz etkilediğini ortaya koymuştur (Demirel, 2014;4926). Dolayısıyla yöneticilerin çalışanlarına monotonluktan uzak, sahip oldukları ihtiyaçlarına uygun çalışma ortamı hazırlamak suretiyle onların işlerine karşı olumlu tutumlar geliştirmelerine imkân sağlamalıdırlar. Bu çalışmanın önemli bir sınırlılığını oluşturan belli bir kurum çalışanlarından ziyade daha geniş katılımlı bir çalışmanın yapılması ve iş doyumunun yanında muhtemel etkileri olabilecek diğer değişkenlerin de kullanılması yaşam doyumuna ilişkin daha geniş bir değerlendirmenin yapılmasına imkân sağlayacaktır.

\section{Kaynakça}

Alghamdi, F.S. (2015). Another Look At Job And Life Satisfaction Among Employees: Evidence From A Developing Country. American Journal Of Industrial And Business Management, 2015/5, 11-19.

Argan, M., Argan, M.T. \& Dursun, M.T. (2018). Examining Relationships Among Well-being, Leisure Satisfaction, Life Satisfaction, and Happiness, International Journal of Medical Research \& Health Sciences, 2018, 7(4): 49-59.

Arıdağ, N.Ç. \& Seydooğulları, S.Ü. (2018). Lise Öğrencilerinin Yaşam Doyumu ve Y1lmazlık Düzeylerinin AnneBaba Tutumlarıyla İlişkisi Açısından İncelenmesi, Hacettepe Üniversitesi Eğitim Fakültesi Dergisi,1-24. doi: 10.16986/HUJE.2018038527

Aşan, Ö. \& Erenler E. (2008). İş Tatmini ve Yaşam Tatmini İlişkisi. Süleyman Demirel Üniversitesi İktisadi ve İdari Bilimler Fakültesi Dergisi, 13 (2), 203-216.

Avşaroğlu, S., Deniz M. E. \& Kahraman A. (2005). Teknik Öğretmenlerde Yaşam Doyumu İş Doyumu ve Mesleki Tükenmişlik Düzeylerinin İncelenmesi. Selçuk Üniversitesi Eğitim Fakültesi Dergisi, 14, 115-129.

Aydıntan, B. \& Koç,H. (2016). The Relationship Between Job Satisfaction And Life Satisfaction: An Empirical Study On Teachers. International Journal of Business And Social Science, 7(10),72-80.

Bergermaier, R., Borg I. \& Champoux J. E. (1984). Structural Relationships Among Facets Of Work, Nonwork And General Well-Beingi. Work And Occupations, 11 (2), 163181.

Bozkurt, Ö. \& Bozkurt İ. (2008). İş Tatminini Etkileyen İşletme İçi Faktörlerin Eğitim Sektörü Açısından Değerlendirilmesine Yönelik Bir Alan Araştırması. Doğuş Üniversitesi Dergisi, 9 (1), 1-18.

Brayfield, A.H. \& Rothe, H.F. (1951). An Index Of Job Satisfaction, Journal of Applied Psychology. 35(5), 307311.

Büte, M. (2011). Nepotizm ve İş Tatmini İlişkisinde İş Stresinin Aracı Rolü Var midır?. Dumlupınar Üniversitesi Sosyal Bilimler Dergisi, 29, 175-184.

Büyüköztürk, Ş. (2003). Sosyal Bilimler İçin Veri Analizi EI Kitabı. 3b., Ankara: Pegem Yayıncılık.

Champoux, J. E. (1981). A Sociological Perspective On Work İnvolvement, International Review Of Applied Psychology. 30 (1), 65-86. 
Cindiloğlu, M., Polatcı, S., Özçalık, F. \& Gültekin, Z. (2017). İşyeri Yalnızlığının İş ve Yaşam Tatminine Etkisi: LiderÜye Etkileşiminin Aracılık Rolü. Ege Akademik Bakış, 17(2), 191-200.

Çarıkçı, İ. H. (2000). Çalışanların İş Tatminlerini Etkileyen Kişisel Özellikler: Süpermarket Çalışanları Üzerinde Bir Araştırma. Süleyman Demirel Üniversitesi İktisadi İdari Bilimler Fakültesi Dergisi, 5 (2), 155-168.

Dağl1, A. \& Baysal, N. (2016). Yaşam Doyumu Ölçeğinin Türkçe'ye Uyarlanması: Geçerlik ve Güvenirlik Çalışması. Elektronik Sosyal Bilimler Dergisi, 15(59):1250-1262.

Demirel, H. (2014), An İnvestigation Of The Relationship Between Job And Life Satisfaction Among Teachers, Social And Behavioral Sciences, 116, 4925-4931

Diener, E., Emmons, R.A, Larsen, R.J. \& Griffin, S. (1985), The Satisfaction With Life Scale, Journal of Personality Assessment, 49(1), 71-75.

Selen Doğan, S. \& Aslan, M. (2018). Psikolojik Sermaye, İçsel Motivasyon ve İș Tatmini İlișkisi. Ömer Halisdemir Üniversitesi İktisadi ve İdari Bilimler Fakültesi Dergisi, 11(3), 112-125.

Donuk, B. (2009). Özel ve Kamu Sektöründe Görev Yapan Spor Yöneticilerin İş Tatminlerinin Karşılaştırılması. Selçuk Üniversitesi Sosyal Bilimler Enstitüsü Dergisi, 2009/21, 179-185.

Dost, M.T. (2007). Üniversite Öğrencilerinin Yaşam Doyumunun Bazı Değişkenlere Göre İncelenmesi. Pamukkale Üniversitesi Ĕgitim Fakültesi Dergisi, 22, 132143.

Erdoğan, İ. (1996). İşletme Yönetiminde Örgütsel Davranış, İstanbul: Avciol Basım Yayın.

Farrell, D. (1983). Exit, Voice, Loyalty, And Neglect As Responses To Job Dissatisfaction: A Multidimensional Scaling Study. Academy of Management Journal, 26 (4), 596-607.

Garretto, F. (2000). Life Satisfaction Homeostasis And The Role Of Personality. (Erişim:10/09/2018), Https://Nanopdf.Com/Download/Life-Job-SatisfactionRelationship-And-The-Role-Of-Personality_Pdf.

Jalagat, R.(2016). Job Performance, Job Satisfaction, and Motivation: A Critical Review of their Relationship, International Journal of Advances in Management and Economics, 5(6):36-42

Judge T. A., Locke E., Durham C. \& Kluger A. (1998), Dispositional Effects On Job And Life Satisfaction: The Role Of Core Evaluations. Journal of Appliedpsychology, 83 (1), 17-34.
Köker, S. (1991). Normal ve Sorunlu Ergenlerin Yaşam Doyumu Düzeyinin Karşılaştırılması. Yüksek Lisans Tezi, Ankara: Ankara Üniversitesi.

Köksal, O. (2014). İş Doyumu ve Yaşam Doyumu Arasındaki İlişkide Bireysel Farklılıklar. İş ve İnsan Dergisi,1(1), 5362.

Naz, S. (2015). Relationship Of Life Satisfaction And Job Satisfaction Among Pakistani Army Soldiers. İşletme Araştırmaları Dergisi, 7(1), 7-25.

Özdevecioğlu, M. \& Doruk, N. Ç. (2009). Organizasyonlarda İş-Aile ve Aile İş Çatışmalarının Çalışanların İş ve Yaşam Tatminleri Üzerindeki Etkisi. Erciyes Üniversitesi İktisadi Ve İdari Bilimler Fakültesi Dergisi, 33 (Temmuz-Aralık), 69-99.

Özyer, K., Irk E. \& Anaç S. (2015). İş Tatmini ve Yaşam Tatmini İlişkisinde İş Arkadaşlığının Aracılık Rolü. C. $\ddot{U}$. İktisadi ve Ídari Bilimler Dergisi, 16 (1), 261-278.

Polatc1,S. (2015). Örgütsel ve Sosyal Destek Algılarının Yaşam Tatmini Üzerindeki Etkisi: İş ve Evlilik Tatmininin Aracılık Rolü. Ekonomik ve Sosyal Araştırmalar Dergisi, 11(2), 25-44.

Rode, J.C. (2004). Job Satisfaction And Life Satisfaction Revisited: A Longitudinal Test Of An İntegrated Model, Human Relations, 57(9): 1205-1230.

Soylu, Y. \& Kabasakal, Z. (2016). Evli Kadınların Yaşam Doyumunun Evlilik Doyumu ve Çalışma Durumu İle İlişkilerinin İncelenmesi. Eğitim ve Öğretim Araştırmaları Dergisi, 5(4), 215-221

Turgut, E.M. (2010). İş Doyumu ve Yaşam Doyumu İlişkisi ve Ístanbuldaki Devlet Üniversite Hastanelerinde Çalışan Ameliyathane Hemşirelerine Yönelik Bir Araştırma. Yüksek Lisans Tezi, İstanbul: İstanbul Üniversitesi.

Tutcu, A. \& Çelik, M. (2018). Çalışanların Duygusal Sermayelerinin İş Doyumu Üzerine Etkisi. Uluslararası Sosyal Araştırmalar Dergisi, 11(55), 868-880.

Yenihan, B., Öner, M. \& Balcı, B. (2016). İş Doyumu ve Yaşam Doyumunun Demografik Özelliklerle İlişkisi: Sakarya'daki Avm'lerin Çalışanları Üzerine Bir Araştırma. Siyaset, Ekonomi ve Yönetim Araştırmaları Dergisi, 2016, 4(1), 33-49.

Yiğit, R., Dilmaç, B. \& Deniz, M.E. (2011). İş ve Yaşam Doyumu: Konya Emniyetmüdürlüğü Alan Araştırması. Polis Bilimleri Dergisi, 13 (3), 1-18.

Yürür, S. \& Keser, A. (2010). İşe Bağlı Gerginlik İle İş Tatmini İlişkisinde Duygusal Tükenmenin Aracı Rolü. Ankara Üniversitesi SBF Dergisi, 65(4), 165-194. 

